\title{
La revolución confiscada: Teodoro Roosevelt y el nacimiento de la república de Cuba* $^{*}$
}

\author{
Serge Ricard \\ Université de Provence (Francia)
}

Este artículo describe la reacción del presidente de los EE.UU. frente al deterioro del clima político en la isla en 1905-1906 y explica por qué el célebre garrote rooseveltense fue manejado, excepcionalmente, con muchísima precaución, delicadeza y discreción. Evidentemente Cuba tenía para Roosevelt, el imperialista, valor de símbolo. En 1898, no había importado tanto la liberación de los cubanos oprimidos como los imperativos estratégicos de los Estados Unidos en el Nuevo Mundo. Por eso le inquietaban todos los desórdenes "hemisféricos". En 1906, sin embargo, también se preocupaba por las repercusiones previsibles en el extranjero y en el Congrego de los EE.UU. de una nueva intervención norteamericana en el mar Caribe.

\section{Teodoro Roosevelt, el imperialista}

Las elecciones de noviembre de 1904 fueron un éxito personal para Teodoro Roosevelt, el vicepresidente elegido en 1900, que había sucedido a William McKinley el 14 de septiembre 1901, ocho días después de que los disparos de un anarquista hubieran causado a éste una herida fatal. En esta ocasión recibió Roosevelt una consagración presidencial que debía a sus méritos propios. La campaña electoral le dio también la oportunidad de defender la política exterior del Partido Republicano, desde 1898, en Cuba, Puerto Rico y las Filipinas, y de valorar su propia contribución.

Él había sido subsecretario de la Marina de Guerra en 1897-1898; su acción determinada, apoyada sobre un conocimiento excelente de los asuntos técnicos, es considerada, según los historiadores norteamericanos, como mínimo importante, si no decisiva. ${ }^{1} \mathrm{Al}$ estallar la guerra contra España presentó su dimisión de la subsecretaría para ir a combatir en Cuba como teniente coronel de un regimiento de voluntarios famosos, los Rough

* Este trabajo fue presentado en el XI Congreso Internacional de AHILA, Liverpool, 17-22 de septiembre de 1996.

1 Para un análisis del papel del vigésimo sexto presidente de los EE.UU. que toma en cuenta el archivo naval y la historiografía consagrada a su carrera política, consultar Ricard, Serge: Théodore Roosevelt: principes et pratique d'une politique étrangère. Aix-en-Provence, 1991, páginas 223-230, 323-329. El presente trabajo, en su mayor parte, es una adaptación en español de mis investigaciones. 
Riders. Conoció su hora de gloria en la colina de San Juan, lo que garantizó su elección al puesto de gobernador del Estado de Nueva York en 1899.²

\section{Los antecedentes}

Defensor resuelto militante y de la doctrina de Monroe de un "hemisferio" liberado de la presencia colonialista, o puramente militar, de los europeos, temía particularmente las ambiciones germánicas y no disimulaba su desprecio por España; la perspectiva de una guerra sobre Cuba, "la guerra más justa de los últimos cincuenta años", ${ }^{3}$ iba a despertar su antipatía hacia la nación europea que más menospreciaba. Los acontecimientos de 1895-1898 no constituyeron ninguna sorpresa para Teodoro Roosevelt. Estaba preparado desde hacía mucho tiempo. Su visión geopolítica comportaba la eliminación de un insoportable anacronismo: con la excepción de Inglaterra y Francia, discretas en el mar Caribe, y si no se olvidaba que Canadá era, en cierto sentido, un rehén de Washington, es decir, una garantía de buena conducta de parte de Gran Bretaña, España era la única potencia europea sospechosa con territorios en el mar Caribe. Era, pues, necesario echarla de las Américas para borrar este vestigio arcaico de un detestable pasado colonial, y así liberar Cuba del régimen autocrático de "la nación más atrasada de Europa", ${ }^{4}$ como también importaba adquirir las Islas Vírgenes danesas, a fin de disuadir cualquier nueva tentativa de implantanción europea, alemana sobre todo. ${ }^{5}$

Evidentemente, Cuba tenía para Roosevelt, el imperialista, valor de símbolo, quizás a causa de la suma de frustraciones que había llegado a ser para los expansionistas norteamericanos esta vergonzosa ilustración de un siglo de fracasos anexionistas. Además, el futuro presidente estimaba que una administración incompetente y bárbara había transformado la "perla de

2 Es imposible dar aquí la lista completa de las obras que tratan de la vida de Roosevelt antes de la presidencia. Una de las mejores es, sin duda, la de Morris, Edmund: The Rise of Theodore Roosevelt. London, 1979.

3 Roosevelt: The Works of Theodore Roosevelt, ed. Hermann Hagedorn, National Edition, 20 vol., New York, 1926, XIII, págs. 172, 156; XIV, pág. 338; Roosevelt a James Bryce, historiador y amigo inglés, 31 de marzo de 1898, The Letters of Theodore Roosevelt, ed. Elting E. Morison and John M. Blum, 8 vol. Cambridge, 1951-1954, II, pág. 807; Roosevelt a Willam Wingate Sewal, amigo personal desde su estancia con él en el Oeste, 4 de mayo de 1898, The Letters..., II, pág. 823.

4 Roosevelt: The Works..., V, pág. 823.

5 Roosevelt a Alfred Thayer Mahan, presidente del Colegio de Guerra Naval, 3 de mayo de 1897, The Letters..., I, págs. 607-608. 
las Antillas" en la "Armenia" de las Américas, y que la gestión unilateral de la crisis por Madrid era un insulto permanente para EE.UU. El subsecretario de la Marina de Guerra lamentó muchas veces, desde 1895 hasta el principio de las hostilidades, el no ser "el patrón de este gobierno" ${ }^{6}$ Un año antes de la declaración de guerra parecía alegrarse secretamente de la indignación popular, no tanto porque era la expresión de motivos humanitarios, sino porque ofrecía una justificación irresistible para intervenir. No importaba tanto la liberación de los cubanos oprimidos como los imperativos estratégicos de los Estados Unidos en el Nuevo Mundo - la exclusión de Madrid, la adquisición de nuevos territorios, Hawai y Santo Tomás, por ejemplo - y las ventajas militares, en particular la oportunidad de probar el valor del armamento y del ejército norteamericanos.?

\section{EE. UU. y la Cuba "liberada"}

Se recordará que en virtud de la enmienda Teller del 9 de marzo de 1898, adoptada bajo la presión de los antiexpansionistas, el Congreso de los EE.UU. había prometido que Cuba no sería anexionada. Si embargo, un año después la enmienda Platt — cuyas cláusulas fueron encerradas en la nueva Constitución cubana del 12 de junio de 1901 y también en el tratado estadounidense-cubano del 22 de mayo de 1903 - transformó la nueva república en un protectorado virtual, casi un apéndice de los EE.UU. Cuba se comprometía a no arriesgar su independencia a favor de una tercera potencia. En la opinión de Teodoro Roosevelt, no cabía la menor duda de que su país había demostrado magníficamente un auténtico altruismo: "Jamás en la historia de estos últimos años un gran país ha obrado con desinterés igual al que manifestamos en Cuba". ${ }^{8}$

La nación norteamericana no había pedido a los cubanos "absolutamente nada" en compensación, salvo "que en ningún momento prostituyeran su independencia a favor de uno de nuestros competidores extranjeros, o de tal modo que nuestro bienestar fuera amenazado". 9 Sin embargo,

6 Roosevelt a James Bryce, 31 de mayo de 1898, Ibídem, II, pág. 807; Roosevelt a William Wirt Kimball, autor de un plan de guerra en el ministerio de la Marina de Guerra, 19 de noviembre de 1898, Ibídem, I, pág. 717.

7 Roosevelt al senador William Pierce Frye, 31 de marzo de 1898, Ibídem, II, pág. 806; Roosevelt a William W. Kimball, 19 de noviembre de 1897, Ibídem, I, págs. 716-718, 717; Ricard, Roosevelt..., págs. 222-223.

8 Roosevelt, The Works..., XIII, pág. 477.

9 Ibídem. 
mientras alababa la filantropía generosa de su país, Roosevelt se solidarizaba con una política republicana que interiormente él desaprobaba, como debía recordarlo cuando ocurrió el desgobierno de 1906:

[...] ni McKinley ni tampoco el Congreso, al principio de la guerra con España, estaban deseosos de adoptar lo que yo consideraba como una actitud racional, y entonces nos comprometimos con una promesa firme que tuvimos que respetar. ${ }^{10}$

Como sabemos, tras su "liberación" por las tropas estadounidenses, y antes de lograr ser digna de su independencia, según el punto de vista de Washington, Cuba pasó cuatro años, desde el verano de 1898 hasta el de 1902, bajo el mandato de un gobierno de ocupación encabezado inicialmente por el general Leonard Wood, un amigo de Roosevelt y su superior durante la expedición militar en la isla. La intervención no tuvo sólo motivos humanitarios; las compañías norteamericanas que habían invertido capitales en la isla, o que hacían negocio con ella (puesto que Cuba era el primer importador latinoamericano de productos estadounidenses) se habían convertido gradualmente a una solución militar, frente al perjuicio resultante de la lucha de los cubanos por su independencia.

Después de la eliminación de España, el objetivo esencial de la ocupación fue la creación de estructuras administrativas, jurídicas, políticas y económicas más propicias que las antiguas para los intereses mercantiles de Washington. El modelo ideal no podía ser otro que la sociedad industrial de "nuestra gran república anglosajona", como decía el general Wood. Nuevas leyes fueron promulgadas con intención de proteger a las grandes compañías norteamericanas, azucareras, mineras y otras, como General Electric, Union Carbide, United Fruit, Bethlehem Steel, International Telephone and Telegraph, etc.

Un esfuerzo educativo particular acompañó esa revolución modernista, cuya finalidad era la transformación radical de una cultura considerada como inferior. Pero estos "cambios revolucionarios", según una obra reciente, no mejoraron la situación de los cubanos, ya fueran trabajadores o miembros de la clase media. En 1902, la Liga General de Trabajadores Cubanos recibió el apoyo de ambos grupos, cuando denunció la explotación de la isla por empresas extranjeras. El crecimiento del sentimiento nacionalista iba a desarrollarse durante unos treinta años, e iba a alimentar

10 Rosevelt a su amigo Whitelaw Reid, 24 de septiembre de 1906, Archivo de Theodoro Roosevelt, Biblioteca del Congreso, 2. ${ }^{\text {a }}$ serie, cinta n. ${ }^{\circ} 343$. 
varios movimientos revolucionarios; iba a ser la consecuencia más espectacular del control por EE.UU. de la mayoría de las economías de América Central y del Sur, un fenómeno que nunca entendieron los norteamericanos, que siempre confundieron nacionalismo con comunismo. ${ }^{11}$

Lo más irónico, en ese contexto, es que para el nuevo ocupante de la Casa Blanca los problemas económicos correspondían a bajas preocupaciones materiales, y éstos, aunque a lo largo de toda su presidencia se preocupara por la integridad de la vida y los bienes de sus compatriotas en el extranjero - si no personalmente, sí al menos por medio del Departamento de Estado-, pasaban para él a un segundo plano eclipsados por los asuntos estratégicos. La estabilidad de Cuba se inscribía dentro de una visión geopolítica del "hemisferio occidental", en la cual figuraba la construcción del futuro canal de Panamá y su protección. En 1904 y 1905 Roosevelt definió el papel de Washington con respeto a su zona de influencia; con su "corolario a la doctrina de Monroe", suministró a EE.UU. la justificación ideológica y moral que les faltaba para intervenir, sistemáticamente, en lugar de las potencias europeas, en su calidad de "policía del hemisferio", cada vez que ellos lo estimaran necesario; es decir, si cualquier desorden político pusiera en peligro sus intereses vitales y su seguridad.

\section{La independencia vigilada}

El 20 de mayo de 1902, Washington dio término a la ocupación, retirando sus tropas, y Cuba tuvo verdaderamente acceso a la independencia. Paradójicamente, se dio por primer jefe del Estado a Tomás Estrada Palma, líder del Partido Moderado y partidario desde siempre de una anexión por EE.UU. Tres años después, la isla conoció su primera crisis política. El descontento de los obreros y campesinos amenazaba la supervivencia de un gobierno dispuesto sobre todo a defender los privilegios de la burguesía negociante por encima de los de los otros grupos sociales. Las elecciones de diciembre de 1905, la corrupción y la trampa que las caracterizaron, la victoria fraudulenta de los Moderados sobre el Partido Liberal, acabaron de acrecentar la impopularidad de Palma y engendraron una sublevación armada. Incapaz de controlar la situación insurreccional en la isla y opues-

11 O'Brien, Thomas F.: The Revolutionary Mission: American Enterprise in Latin America, 1900-1945. New York, 1996, págs. 206-215. 
to a cualquier compromiso con los rebeldes, el presidente de la república prefirió buscar ayuda fuera, es decir, acudir al protector norteamericano. ${ }^{12}$

\section{Asuntos de política "semi-extranjera"}

Antes de examinar la reacción de Teodoro Roosevelt respecto al episodio de 1906, estos asuntos de política "semi-extranjera", como él llamaba a los problemas cubanos, ${ }^{13}$ me parece útil subrayar que desde el invierno precedente le inquietaba el deterioro del clima político en Cuba. El general de brigada J. Franklin Bell, jefe del estado mayor del ejército estadounidense, había previsto el envío de tres divisiones si la situación exigía esa medida excepcional, y la Casa Blanca había aprobado estos preparativos. ${ }^{14}$ Pero al presidente la necesidad, cada día más probable, de una intervención militar le contrariaba considerablemente. Desde la independencia de la isla tenía miedo a una insurrección como la que acababa de estallar, y le dolía mucho que tres años de tutela norteamericana no hubiesen dado a los cubanos un impulso suficiente para que continuaran "en la vía de la eficiencia y de la justicia”. Además de ataques contra las personas y los bienes, temía el desarrollo de un síndrome revolucionario y el nacimiento de una clase de especialistas de la impugnación y de la violencia, una visión típica de su opinión sobre los latinoamericanos. Informado el 8 de septiembre de 1906 de la inminencia de una llamada de parte del gobierno cubano para que Washington le ayudara, su primera reacción fue la de protestar enérgicamente contra esa demanda y reservarse la opción de no acceder a la súplica de Palma. ${ }^{15}$ En realidad, se encontraba en un lío y no sabía qué hacer:

12 La intervención de 1906 y la nueva ocupación que siguió (1906-1909) es tratada por Allan R. Millett: The Politics of Intervention: The Military Occupation of Cuba, 1906-1909, Columbus, 1968, y Louis A. Pérez, Jr.: Cuba under the Platt Amendment, 1902-1934, Pittsburgh, 1986. Se puede también consultar el informe del ministro de la Guerra, War Department, Bureau of Consular Affairs, Cuban Pacification: Report of William H. Taft, Secretary of War, and Robert Bacon, Assistant Secretary of State, December 11, 1906, 59. ${ }^{\circ}$ Congreso, 2. ${ }^{a}$ sesión, Documento de la Cámara de Representantes n. ${ }^{\circ}$ 2, Apéndice E, y la compilación de documentos diplomáticos publicados por la imprenta del gobierno de los EE.UU. (Government Printing Office): Papers Relating to the Foreign Relations of the United States, 1906, págs. 454-494.

13 Roosevelt a Charles William Eliot, presidente de la Universidad de Harvard, 22 de septiembre de 1906, The Letters..., V, pág. 419.

14 Ibídem, V, pág. 391, n. 1; Roosevelt a James Franklin Bell, 1. ${ }^{\circ}$ de septiembre de 1906, Ibídem, V, págs. 391-392.

15 Roosevelt a George Otto Trevelyan, el célebre historiador inglés, 9 de septiembre de 1906, Ibídem, V, pág. 401. 
De un lado, no podemos tolerar que Cuba sea presa continuamente de desorden y anarquía; de otro lado, me repugna la idea de asumir cualquier control de la isla, como es el caso en Puerto Rico y las Filipinas. ${ }^{16}$

Imaginaba la impresión desastrosa que produciría en el extranjero otra intervención militar de Washington y las acusaciones de colonialismo que resultarían de su decisión, teniendo en cuenta el recelo de los europeos, para quienes desde el principio Washington quería poseer "la perla de las Antillas". Él siempre había querido demostrar la superioridad de los cubanos sobre los "salvajes" filipinos y nunca había pensado tratarlos de la misma manera. Al contrario, le parecía posible llevar las Filipinas al nivel de Cuba. ${ }^{17}$ También se preocupaba por las repercusiones previsibles en el Congreso de los EE.UU., especialmente en el Senado, donde tenía muchos enemigos, muy enfurecidos con su política extranjera intervencionista, en 1903 en Panamá y en Santo Domingo dos años después.

Por todas estas razones no quería Roosevelt interponerse, sino por absoluta necesidad, un extremo que su ministro de la Guerra, William Howard Taft, y el asistente del secretario de Estado, Robert Bacon, ambos enviados en misión a La Habana, debían juzgar. Es poco decir que jamás el célebre garrote rooseveltense había sido manejado con tanta precaución, delicadeza y discreción. ${ }^{18}$ El presidente norteamericano estaba muy reticente, como lo demuestra su primera iniciativa. A fin de disuadir a los insurgentes pensó, en primer lugar, en advertir a los cubanos sobre las consecuencias inevitables de la anarquía, es decir, la intervención contra su voluntad de los EE.UU. ${ }^{19}$

La situación en la isla era caótica: Palma buscaba un pretexto para dimitir, pero el vicepresidente y el gabinete daban la impresión de no tener ganas de mantener la continuidad del Estado. El 14 de septiembre Roosevelt escribió solemnemente a don Gonzalo de Quesada, ministro plenipotenciario de Cuba en Washington; la carta presidencial fue transmitida

\section{Ibídem.}

17 Ibídem.

18 A pesar de sus acusaciones de "cinismo", "hipocresía" y "duplicidad" así lo admite Jorge Ibarra en: "Agosto de 1906. Una intervención amañada", Revista de la Biblioteca Nacional José Martí, 15.1, Enero-Abril 1973, págs. 161-186. Según una interpretación poco convincente de Christopher A. Abel en "Controlling the Big Stick: Theodore Roosevelt and the Cuban Crisis of 1906", Naval War College Review, 40.3.319, Summer 1987, págs. 88-98, fue incapaz el teórico del "gran garrote" de controlar el celo intempestivo en Cuba de varios oficiales de la marina de guerra estado-unidense.

19 Roosevelt a Robert Bacon, subsecretario de Estado, 10 de septiembre de 1906, The Letters..., V, págs. 402-403. 
al encargado de negocios norteamericano en La Habana con instrucciones de entregarla a Tomás Estrada Palma y de hacerla publicar en la prensa de la isla. Eso le parecía constituir el mejor medio de comunicación no sólo con las autoridades gubernamentales, sino también con el pueblo cubano. ${ }^{20}$

Roosevelt se enorgullecía de haber proclamado la independencia de Cuba y retirado las tropas estadounidenses en 1902; recordaba su admiración por el pueblo cubano y se inquietaba al ver que la anarquía comprometía siete años de prosperidad, cuatro de ellos como nación soberana. Los EE.UU. no querían nada más que la continuidad del desarrollo de la isla, de manera ordenada y respetuosa de las libertades individuales. Conminaba a los cubanos a no abandonarse al reflejo insurreccional, a recobrarse, a acallar sus diferencias, a unirse, a demostrar así su aptitud para ocuparse de sus propios asuntos, a fin de evitar "la necesidad de una intervención exterior".

El tercer artículo del tratado norteamericano-cubano daba explícitamente a Washington el derecho de intervenir para mantener o imponer un gobierno capaz de proteger las vidas, los bienes y las libertades individuales. Con esa última mención se proponía intimidar a los insurgentes con la intención de salvaguardar los intereses de sus compatriotas, pues afirmaba tener informaciones dignas de confianza sobre daños y destrucciones inflingidos a los bienes norteamericanos. Concluía con la necesidad imperativa de poner fin a las hostilidades y de un acuerdo que garantizase una paz duradera. $^{21}$

\section{Vacilaciones presidenciales}

La correspondencia de Roosevelt durante la crisis, a mediados de septiembre de 1906, reflejaba su perplejidad y era una clara muestra de su deseo de comprender el origen de los sobresaltos políticos que sacudían a Cuba. Instintivamente, su primera reacción fue sostener el poder existente, el cual continuaría beneficiándose de una opinión favorable por su parte, después de que se hubiera impuesto la necesidad de consentir el hacer concesiones a la oposición. Aunque finalmente se daría cuenta de que la causa principal de la inestabilidad del momento era la obstinación de Palma y de los Moderados, no manifestaría ninguna simpatía especial hacia los rebel-

20 Roosevelt a Bacon, 14 de septiembre de 1906, Ibídem, V, pág. 411.

21 Roosevelt a don Gonzalo de Quesada, ministro de Cuba en Washington, 14 de septiembre de 1906, Ibídem, V, págs. 411-413. 
des, sino que tomaría en cuenta sus reclamaciones y exigencias, resignándose ante la falta de una solución que pudiera salvar las apariencias constitucionales.

Al principio aprobó el plan del secretario de la Guerra, Taft, que preveía el establecimiento de un ejecutivo provisional, la dimisión de la mitad del senado y de la cámara de diputados y la reintegración de los oficiales municipales que habían sido despedidos abusivamente, además de la organización de una votación según una nueva ley electoral. En su opinión, el Partido Moderado no podría negar estas condiciones y los insurgentes, por su parte, tendrían que convencerse de la idea de que tropas norteamericanas desembarcarían en la isla para defender las vidas humanas si aumentaban demasiado su presión. Curiosamente, no quería Roosevelt dirigir un ultimátum en caso de intransigencia de parte de los rebeldes; prefería solicitar contrapropuestas, de modo que el público norteamericano pudiera observar que su gobierno hacía todo lo que estaba a su alcance, excepto el recurso a la fuerza, para conseguir un acuerdo aceptable por todos.

Esperaba convencer a Palma de quedarse, por lo menos provisionalmente, a la cabeza de la república, nada más que el tiempo necesario para inaugurar "el nuevo gobierno transitorio" encargado de cumplir el plan de paz. Quería, sobre todo, de manera casi obsesiva, que fuesen salvadas las apariencias constitucionales, un reflejo legitimista que, al cabo, la terquedad de los Moderados no le permitiría satisfacer. Paralelamente, Taft tenía que prevenir a los insurgentes contra toda tentación extremista de su movimiento, a riesgo de asumir la responsabilidad del derribo de la república y además la de su propia perdición, puesto que Estados Unidos estarían obligados a intervenir. ${ }^{22}$

Irritaba a Roosevelt la incertidumbre de la situación política descrita en los telegramas de su secretario de la Guerra, sobre el terreno. En realidad, se daba cuenta con cierto retraso de los graves errores e injusticias cometidos por el gobierno del presidente Palma. Le enfurecía que la legación norteamericana le hubiera informado tan mal, y que el ministro se hubiera ido de vacaciones a Europa el día antes de la sublevación.

El 25 de septiembre de 1906 se decidió por la solución de un desembarco de tropas para dar término a la carencia, o más exactamente la vacante, del poder, pero aconsejó a Taft no hablar de represión de la insurrección,

22 Roosevelt a Taft, secretario de la Guerra, 22 y 25 de septiembre de 1906, The Letters, V, págs. 419, 422-423. 
excluir la palabra "intervención" de cualquier documento o proclamación, y sellar mediante un acuerdo con los jefes rebeldes la sustitución temporal de la autoridad del presidente dimisionario por la militar norteamericana, con objeto de realizar el programa que Taft y ellos habían pactado. ${ }^{23} \mathrm{El} 26$, el día antes de la intervención de Washington, lo bombardeó con directivas y llamadas a la prudencia. Era capital que la gente entendiera, nacional e internacionalmente, que Estados Unidos no proyectaban atentar contra la independencia de Cuba.

No olvidaba Roosevelt la proximidad de la elecciones legislativas y senatoriales de noviembre; también contaba con los asaltos en el Congreso de una oposición virulenta, sin duda dirigida por el senador Joseph B. Foraker, su detractor más persistente en la cámara alta. Más que acusaciones extranjeras de imperialismo hipócrita, temía entonces las reacciones interiores; por eso no quería dramatizar y recomendaba una intervención a escondidas. Desembarcadas las tropas, Taft tendría que subrayar el vacío de poder y la necesidad de mantener el orden en la isla; tendría que insistir sobre la defensa legítima de los intereses norteamericanos y, sobre todo, en el carácter provisional de la misión estadounidense, cuyo objetivo esencial era establecer un gobierno de transición. Habría que limitar el número de guarniciones, a fin de no dar la impresión desagradable de que se trataba de una ocupación, ni tampoco de hostilizar a los insurrectos, a quienes le ligaba un acuerdo que, moralmente, ponía a EE.UU. en posición de fuerza. ${ }^{24}$

De esa manera Roosevelt deseaba disfrazar el aspecto militar de la operación y crear la ilusión de una mediación consensuada. Esperaba que la intervención así circunscrita bastaría, que los insurgentes no decidirían luchar contra el ocupante o, peor, lanzarse a guerrillear. Aun cuando admitía la profunda responsabilidad del gobierno de Tomás Estrada Palma y la realidad de las causas de resentimiento popular, era incapaz, por principios, de aceptar "el espíritu insurreccional" y el recurso a la violencia política. Nunca pudo comprender Roosevelt que la violencia de los oprimidos resulta, a menudo, de violaciones de la legalidad por sus opresores. Como conservador legalista de siempre, lamentaba en el caso presente el haber parecido respaldar el recurso a la ilegalidad y servido la causa insu-

23 Roosevelt a Taft, 25 de septiembre de 1906, Ibídem, V, pág. 423.

24 Telegramas de Roosevelt a Taft, 26 de septiembre de 1906, Ibídem, págs. 424-426. El presidente quería, sobre todo, que no se derramara sangre entre norteamericanos y cubanos. Los combates tenían que desarrollarse exclusivamente entre cubanos. Roosevelt a Taft, 2 de octubre de 1906, Ibídem, págs. 437-438. 
rreccional. Se consolaba pensando que lo peor había sido evitado, la llegada al poder de los "revolucionarios", aunque, moderadamente optimista, no excluía complicaciones. También temía que los cubanos, en adelante, utilizaran la técnica del golpe para deshacerse de cualquier gobierno impopular. ${ }^{25}$

\section{Un garrote pequeño...}

Hombre de certidumbres, Teodoro Roosevelt conoció excepcionalmente en este asunto la duda y la perplejidad, y consultó a sus colaboradores mucho más a menudo de lo que lo hacía habitualmente. Su evaluación de la situación se basó únicamente en los informes de su ministro de la Guerra y amigo, William H. Taft, antiguo gobernador de las Filipinas, en quién tenía una confianza absoluta. Escogió finalmente, de mala gana, la medida intervencionista, pero fue fiel a su práctica política y a su concepción de la eficacia, en el sentido de que dejó de vacilar una vez que hubo tomado su decisión y, dando su firma en blanco a Taft, asumió la responsabilidad total de la operación y todas las consecuencias. ${ }^{26}$ Como siempre, exhibió después una intensa autosatisfacción por la manera elegida para resolver la crisis, la intimidación discreta. El envío a Cienfuegos de unos buques y de menos de doscientos soldados había sido suficiente para restablecer la paz civil, sin oposición por parte de los insurgentes. Si no hubiesen intervenido los EE.UU., si hubiesen prometido no emplear la fuerza bajo cualquier pretexto, como sugería William Jennings Bryan, líder de los Demócratas, "la isla entera estaría hoy a sangre y a fuego". El éxito de su política demostraba la justeza de su célebre método: evidenciar su determinación de recurrir a la fuerza si una situación lo exigiera para que el uso de la fuerza no fuera necesario. ${ }^{27}$

Taft ejerció brevemente las funciones de gobernador provisional, hasta que lo reemplazara Charles Magoon, antiguo ministro en Panamá y gobernador de la zona del canal. ${ }^{28}$ La segunda ocupación de Cuba se terminó

25 Roosevelt a Taft, 26 de septiembre de 1906, Ibídem, V, págs. 424-426.

26 Ibídem.

27 Roosevelt a Henry Cabot Lodge, líder de los Republicanos en el Senado, y su alter ego en política exterior, 27 de septiembre de 1906, Ibídem, V, págs. 427-429; a Joseph Benson Foraker, 28 de septiembre de 1906, Ibídem, V, págs. 429-432; Roosevelt, The Works..., XV, págs. 388-391.

28 Evoca Roosevelt la preocupación de Cuba en sus tres últimos "mensajes anuales". Roosevelt, Ibídem, XV, págs. 388-391, 482, 539. 
en los últimos días de enero de 1909, después de dos años de relativa tranquilidad y prosperidad y de calma política, a pesar de que los acontecimientos de los decenios siguientes demostrarían que la mayoría de los problemas y frustraciones permanecían. Cinco semanas después Roosevelt entregó la presidencia a Taft. La sincronización había sido perfecta. Lo de la opinión de los cubanos, como la responsabilidad de los EE.UU. en el futuro de la isla, es otra historia.... ${ }^{29}$

29 Sobre el resultado inmediato y el impacto histórico de la segunda ocupación, se puede leer la conclusión de Millett, The Politics of Intervention..., págs. 256-270. 